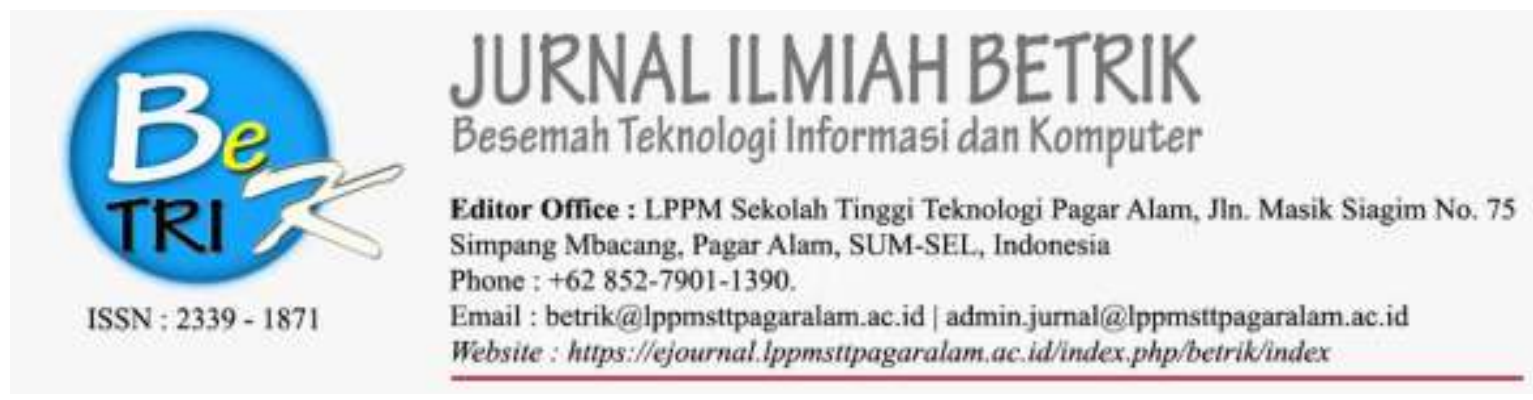

\title{
ANALISIS DAN IMPLEMENTASI DESAIN JARINGAN HOTSPOT BERBASIS MIKROTIK MENGGUNAKAN METODE NDLC (NETWORK DEVELOPMENT LIFE CYCLE) PADA BPU BAGAS RAYA LUBUKLINGGAU
}

\author{
Rudi Kurniawan \\ STMIK Mura Lubuklinggau \\ Jl. Jend. Besar. H.M. Soeharto Km.13 rt.01 kel. Lubuk Kupang Kec. Lubuk Linggau selatan 1 \\ Sur-el:khurniawan.ruenta@gmail.com
}

\begin{abstract}
Today many routing system is used, from free (free) until the pay, from easy to difficult in the system configuration. One of them will be discussed is MikroTikRouterOS, the router operating system currently in use by the cafe-cafe, offices or other agencies. MikroTikRouterOS is a reliable network routers, equipped with a variety of features and tools, both for wired and wireless networks (LAN). With the development of systems using NDLC method, makes the design of the design of these hotspots are becoming more detailed and structured.
\end{abstract}

Keywords: MikrotikRouterBoard, NDLC

\begin{abstract}
Abstrak : Dewasa ini banyak sistem routing yang digunakan, dari yang gratis (free) sampai yang berbayar, dari mudah sampai yang susah dalam sistem konfigurasinya. Salah satunya yang akan kita bahas adalah MikroTikRouterOS, yaitu sistem operasi router yang sekarang ini banyak di gunakan oleh warnet-warnet, kantor-kantor ataupun instansi-instansi lain. MikroTik RouterOS merupakan routernetwork yang handal, dilengkapi dengan berbagai fitur dan tools, baik untuk jaringan kabel maupun jaringan tanpa kabel (wireless). Dengan pengembangan sistem menggunakan Metode $N D L C$, menjadikan desain perancangan hotspot ini menjadi lebih terperinci dan terstruktur.
\end{abstract}

Keywords::MikrotikRouterBoard, NDLC

\section{PENDAHULUAN}

Yayasan Abdi Karya (YADIKA) didirikan oleh dua tokoh masyarakat yakni Dr.Sutan Raja D.L Sitorus dan Ny.L.Siagaan, B.Sc, PADA TANGGAL 14 Februari 1976. Adapun maksud dan tujuan didirikanya YADIKA adalah mencerdaskan kehidupan bangsa dan memajukan kesejahteraan umum dalam rangka ikut serta mewujudkan masyarakat indonesia adil dan makmur berdasarkan pancasila dan UUD 1945.

BPU (Balai Pertemuan Umum) Yadika Lubuklinggau merupakan fasilitas yang dimiliki oleh Yayasan Abdi Karya berupa gedung 
pertemuan dan aula berstandar nasional yangdapat digunakan untuk masyarakat umum di kawasan kota Linggau.

Dengan luas ruangan utama yang cukup besar, yakni dapat menampung undangan sampai 2000 kursi menjadikan magnet tersendiri bagi masyarakat kota Lubuklinggau yang ingin mengadakan acara di gedung tersebut, ditambah lagi fasilitas parkiran yang mencapai 300 mobil yang cukup besar. Maka dari itu perlu disediakan fasilitas HotSpot bagi penyewa untuk mengakses internet.

Dewasa ini banyak sistem routing yang digunakan, dari yang gratis (free) sampai yang berbayar, dari mudah sampai yang susah dalam sistem konfigurasinya. Salah satunya yang akan kita bahas adalah MikroTik RouterOS, yaitu sistem operasi router yang sekarang ini banyak di gunakan oleh warnet-warnet, kantor-kantor ataupun instansi-instansi lain. MikroTik RouterOS merupakan router network yang handal, dilengkapi dengan berbagai fitur dan tools, baik untuk jaringan kabel maupun jaringan tanpa kabel (wireless).

Atas dasar kondisi inilah, penulis tertarik untuk melakukan peningkatan efisiensi perancangan jaringan komputer di BPU Bagas Raya Yadika Lubuklinggau dengan menggunakan Jaringan Nirkabel berbasis MikroTik, sehingga penggunaan dan efisiensi jaringan dapat dimaksimalkan. Untuk merealisasikan hal tersebut, penulis akan melakukan penelitian yang berjudul "Analisis dan Implementasi Desain Jaringan Hotspot Berbasis Mikrotik Menggunakan Metode NDLC (Network Development Life Cycle) Pada BPU Bagas Raya Lubuklinggau”.

\section{METODOLOGI PENELITIAN}

\subsection{Pengertian Jaringan}

Menurut Herlambang (2008), Jaringan komputer adalah sekelompok otonom yang saling menggunakan protokol komunikasi melalui media komunikasi sehingga dapat berbagi data, informasi, program aplikasi, dan perangkat keras serta memungkinkan saling berkomunikasi secara elektronik.

Pada saat awal ditemukan jaringan komputer, yang saling terhubung hanyalah beberapa komputer dalam area tertentu yang membentuk suatu jaringan komputer lokal. Kemudian masing-masing jaringan lokal ini saling dihubungkan untuk membentuk suatu jaringan komputer yang lebih besar lagi. Pada masa itu area yang dapat dijangkau oleh jaringan komputer masih terbatas dikarenakan kendala infrastruktur. Sekarang ini, dengan ditemukannya internet maka komputer di seluruh dunia dapat saling berbagi dan bertukar informasi dengan cepat dan lebih efektif. Perkembangan jaringan komputer ini, menciptakan beberapa alat yang dikembangkan untuk kepentingan sistem jaringan komputer. Beberapa alat jaringan komputer diantaranya server, router, kartu jaringan, repeater hingga sistem pengkabelan dan sebagainya.

Dengan adanya alat-alat tersebut maka kecepatan yang dapat dicapai untuk pertukaran data semakin tinggi. Teknologi yang digunakan untuk media transmisi juga berkembang semakin baik. Yang semula antar komputer hanya dapat dihubungkan dengan menggunakan kabel, kini bisa menggunakan gelombang elektromagnetik 
yang sering disebut dengan jaringan wireless.

Ada beberapa jenis jaringan, yaitu :

\section{Local Area Network (LAN)}

LAN adalah jaringan yang dibatasi oleh area yang relatif kecil, umumnya dibatasi oleh area lingkungan.

\section{Metropolitan Area Network (MAN)}

MAN biasanya meliputi area yang lebih besar dari LAN, misalnya antar wilayah dalam satu propinsi yang menggabungkan jaringan LAN.

\section{Wide Area Network (WAN)}

WAN adalah jaringan yang lingkupnya biasanya sudah menggunakan sarana satelit ataupun kabel bawah laut.

\subsection{MikroTik}

Menurut Herlambang (2008), mikrotik adalah sistem operasi independen berbasiskan Linux khusus untuk komputer yang difungsikan sebagaiRouter, yang dapat dijadikan sebagai gateway network yang handal, mencakup bebagai fitur lengkap untuk network dan wireless, serta tidak membutuhkan spesifikasi komputer yang tinggi.

Mikrotik didesain untuk memberikan kemudahan bagi penggunanya. Administrasinya bisa dilakukan melalui Windows Application (WinBox). Selain itu instalasi dapat dilakukan pada PC (Personal Computer). PC yang akan dijadikan router mikrotik pun tidak memerlukan resource yang cukup besar untuk penggunaan standar, misalnya hanya sebagai gateway. Untuk keperluan beban yang besar (network yang kompleks, routing yang rumit dan lain-lain) disarankan untuk mempertimbangkan pemilihan resource $P C$ yang memadai. Sistem operasi ini juga sudah ada yang tertanam pada routerboard.

\subsection{Wifi}

Wi-Fi merupakan kependekan dari Wireless Fidelity, yang memiliki pengertian yaitu sekumpulan standar yang digunakan untuk Jaringan Lokal Nirkabel (Wireless Local Area Networks - WLAN) yang didasari pada spesifikasi IEEE 802.11 (Ramadhan : 2006). Standar terbaru dari spesifikasi 802.11a atau b, seperti $802.11 \mathrm{~g}$, saat ini sedang dalam penyusunan, spesifikasi terbaru tersebut menawarkan banyak peningkatan mulai dari luas cakupan yang lebih jauh hingga kecepatan transfernya.

Awalnya Wi-Fi ditujukan untuk penggunaan perangkat nirkabel dan Jaringan Area Lokal (LAN), namun saat ini lebih banyak digunakan untuk mengakses internet. Hal ini memungkinan seseorang dengan komputer dengan kartu nirkabel (wireless card) atau Personal Digital Assistant (PDA) untuk terhubung dengan internet dengan menggunakan titik akses (atau dikenal dengan hotspot) terdekat.

Wi-Fi dirancang berdasarkan spesifikasi IEEE 802.11. Sekarang ini ada empat variasi dari 802.11, yaitu:

- $\quad 802.11 \mathrm{a}$

- $802.11 b$

- $\quad 802.11 \mathrm{~g}$

- $802.11 \mathrm{n}$

Di banyak bagian dunia, frekuensi yang digunakan oleh Wi-Fi, pengguna tidak diperlukan untuk mendapatkan izin dari pengatur lokal (misal, Komisi Komunikasi Federal di A.S.). 802.11a menggunakan frekuensi yang lebih tinggi dan oleh sebab itu daya jangkaunya lebih sempit, lainnya sama. 
Versi Wi-Fi yang paling luas dalam pasaran AS sekarang ini (berdasarkan dalam IEEE $802.11 \mathrm{~b} / \mathrm{g}$ ) beroperasi pada $2.400 \mathrm{MHz}$ sampai 2.483,50 MHz.

Dengan begitu mengijinkan operasi dalam 11 channel (masing-masing $5 \mathrm{MHz}$ ), berpusat di frekuensi berikut:

Channel $1-2,412 \mathrm{MHz}$;

Channel 2-2,417 MHz;

Channel $3-2,422 \mathrm{MHz}$;

Channel 4 - 2,427 MHz;

Channel 5-2,432 MHz;

Channel 6-2,437 MHz;

Channel 7 - 2,442 MHz;

Channel 8-2,447 MHz;

Channel 9-2,452 MHz;

Channel $10-2,457 \mathrm{MHz}$;

Channel $11-2,462 \mathrm{MHz}$

Secara teknis operasional, Wi-Fi merupakan salah satu varian teknologi komunikasi dan informasi yang bekerja pada jaringan dan perangkat WLAN (wireless local area network). Dengan kata lain, Wi-Fi adalah sertifikasi merek dagang yang diberikan pabrikan kepada perangkat telekomunikasi (internet) yang bekerja di jaringan WLAN dan sudah memenuhi kualitas kapasitas interoperasi yang dipersyaratkan.

Teknologi internet berbasis Wi-Fi dibuat dan dikembangkan sekelompok insinyur Amerika Serikat yang bekerja pada Institute of Electrical and Electronis Engineers (IEEE) berdasarkan standar teknis perangkat bernomor $802.11 \mathrm{~b}$, 802.11a dan 802.16. Perangkat Wi-Fi sebenarnya tidak hanya mampu bekerja di jaringan WLAN, tetapi juga di jaringan Wireless Metropolitan Area Network (WMAN).
Karena perangkat dengan standar teknis 802.11b diperuntukkan bagi perangkat WLAN yang digunakan di frekuensi $2,4 \mathrm{GHz}$ atau yang lazim disebut frekuensi ISM (Industrial, Scientific dan Medical). Sedang untuk perangkat yang berstandar teknis 802.11a dan 802.16 diperuntukkan bagi perangkat WMAN atau juga disebut Wi-Max, yang bekerja di sekitar pita frekuensi $5 \mathrm{GHz}$.

Ada 2 mode akses koneksi Wi-fi, yaitu :

a. Ad-Hoc. Mode koneksi ini adalah mode dimana beberapa komputer terhubung secara langsung, atau lebih dikenal dengan istilah Peer-to-Peer. Keuntungannya, lebih murah dan praktis bila yang terkoneksi hanya 2 atau 3 komputer, tanpa harus membeli access point.

b. Infrastruktur. Menggunakan Access Point yang berfungsi sebagai pengatur lalu lintas data, sehingga memungkinkan banyak Client dapat saling terhubung melalui jaringan (Network).

\subsection{Network Development Life Cycle (NDLC)}

Dalam penelitian ini, penulis menggunakan pendekatan terhadap model Network Development Life Cycle (NDLC)dapat digambarkan di dalam diagram berikut : 


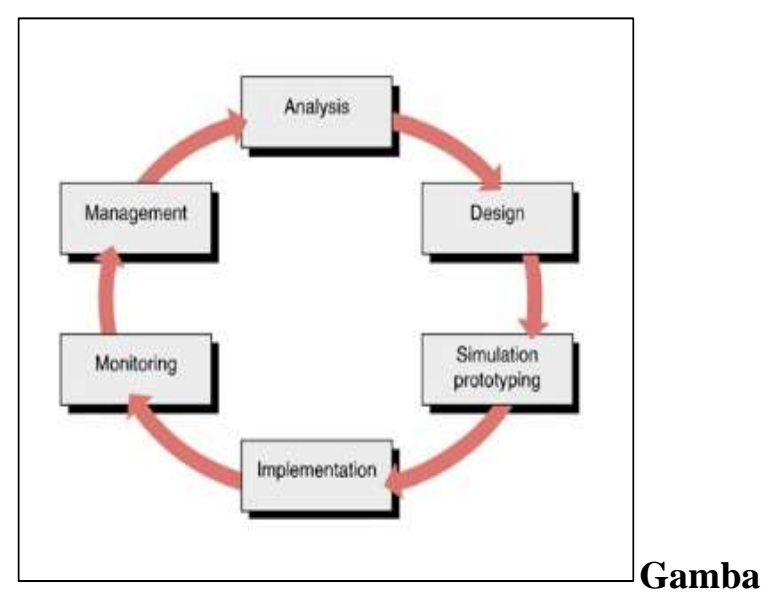

r 1. NDLC Model

NDLC mendefinisikan siklus proses perancangan atau pengembangan suatu sistem jaringan komputer (Goldman et : 2001). NDLC mempunyai elemen yang mendefinisikan fase, tahapan, langkah atau mekanisme proses spesifik. Kata cycle merupakan kunci deskriptif dari siklus hidup pengembangan sistem jaringan yang menggambarkan secara keseluruhan proses dan tahapan pengembangan sistem jaringan yang berkesinambungan (Goldman et : 2001).

NDLC dijadikan metode yang digunakan sebagai acuan (secara keseluruhan atau secara garis besar) pada proses pengembangan dan perancangan sistem jaringan komputer Metode Perancangan yang penulis gunakan adalah Network Development Life Cycle (NDLC) yang merupakan suatu pendekatan proses dalam komunikasi data yang menggambarkan siklus yang awal dan akhirnya dalam membangun sebuah jaringan komputer. Tahapan dalam metode ini, yaitu :

\section{a. Analisis (Analysis)}

Tahap ini dibutuhkan analisa permasalahan yang muncul, analisa keinginan user serta kebutuhan hardware yang akan digunakan dan analisa topologi jaringan yang sudah ada saat ini.

\section{b. Perancangan (Design)}

Dari data-data yang didapatkan sebelumnya, tahap Design ini akan membuat gambar design topologi jaringan interkoneksi yang akan dibangun, diharapkan akan memberikan gambaran seutuhnya dari kebutuhan yang ada. Design bisa berupa desain struktur topologi, desain akses data, desain tata layout perkabelan, dan sebagainya yang akan memberikan gambaran jelas tentang proyek yang akan dibangun.

c. Simulasi (Simulation Prototyping)

Melakukan penerapan sistem dalam sekala kecil atau tahap uji coba pada sistem jaringan yang akan dibangun

d. Implementasi (Implementation)

Dalam implementasi penulis akan menerapkan semua yang telah direncanakan dan di design sebelumnya. Implementasi merupakan tahapan yang sangat menentukan dari berhasil / gagalnya proyek yang akan dibangun.

\section{e. Monitoring}

Setelah implementasi tahapan monitoring merupakan tahapan yang penting, agar jaringan komputer dan komunikasi dapat berjalan sesuai dengan keinginan dan tujuan awal dari user pada tahap awal analisis, maka perlu dilakukan kegiatan monitoring. Monitoring bisa berupa melakukan pengamatan untuk Memantau traffic yang berjalan di jaringan sudah sesuai dengan semestinya, melihat koneksi yang aktif pada jaringan dan melihat hasil pengukuran bandwidth pada keseluruhan jaringan.

\section{f. Management}


Pada tahap manajemen ini akan dilakukan beberapa langkah pengelolaan agar sistem yang telah dibangun dapat berjalan sesuai dengan yang diharapkan.

\subsection{Analisa Sistem}

Rancangan dan Desain Keseluruhan area gedung dapat dimaksimalkan dengan membuat titik-titik area Wi-Fi khususnya pada 2 ruangan pertemuan pada lantai 1 dan ruang pertemuan utama pada lantai 2 , sehingga menjadi lebih fleksibel.

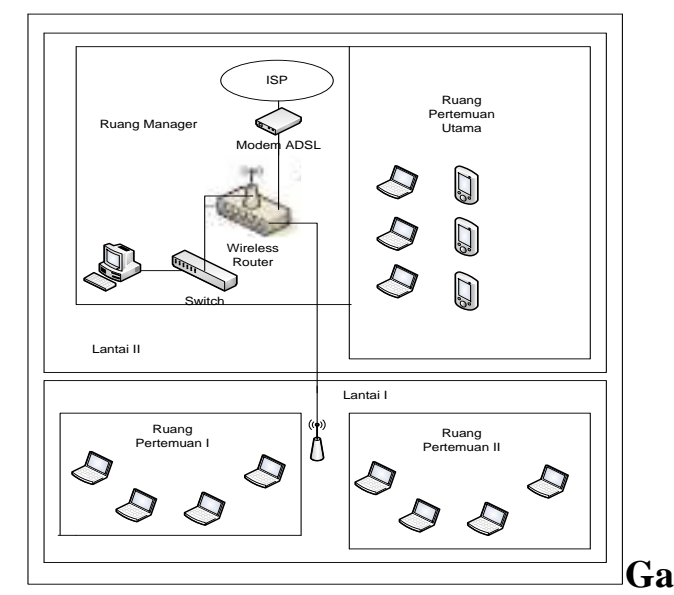

mbar 2. Topologi Jaringan

Dari gambar diatas, jaringan internet dari modem ISP (Internet Service Provider) langsung terhubung ke Router Board, di Router Boardakan diatur seluruh konfigurasi jaringan termasuk hak akses pengguna dan keamanan jaringan terhadap setiap client. Kemudian Router Board langsung terhubung ke switch. Switch disini merupakan suatu konsentrator yang akanmenghubungkan komputer yang ada di ruangan manager, Access Point untuk lantai II didapat dari router mikrotik yang menggunakan access point, dan lantai I langsung terhubung dengan Access Point yang terhubung dengan menggunakan kabel UTP Cat 5e dengan konfigurasi kabel Straight.

\section{HASIL}

\subsection{Implementasi}

Tahapan selanjutnya yaitu implementasi atau penerapan rancangan topologi dan rancangan sistem pada lingkungan nyata.

\section{Konfigurasi Pengaturan Mikrotik Routerboard}

Agar sistem dapat berjalan seperti yang diharapkan, maka diperlukan pengaturan/ setting routerboard. Adapaun tahapan dalam pengaturan ini antara lain :

1. Buka Windows untuk konfigurasi router mikrotik.

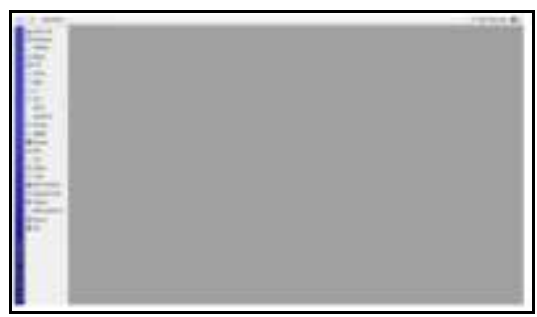

\section{Gambar 3. Tampilan windows mikrotik}

2. Pilih menu interface untuk konfigurasi internet dan hotspot

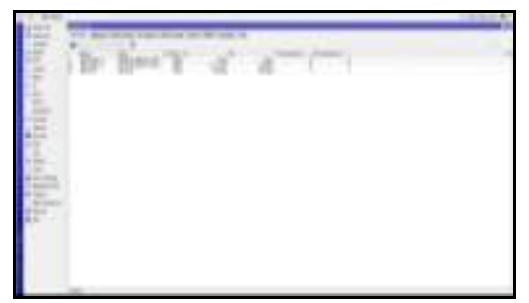

Gambar 4. Tampilan menu interface

3. konfigurasiinterface wireless yang digunakan sebagai access point, mode yang di gunakan adalah mode Access Point bridge agar bisa berfungsi sebagaiAccess Point.

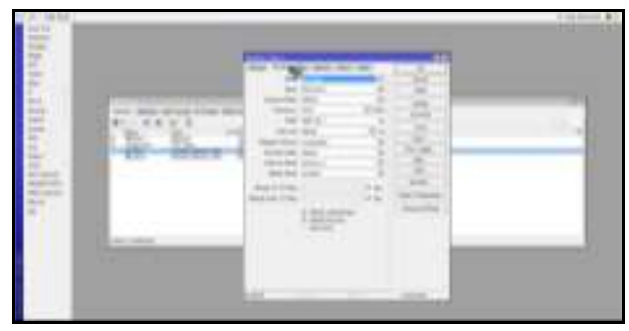


Gambar 5. Tampilan menu interface wireless

\section{$\boldsymbol{A P}$}

4. Buka menu DHCP Client untuk konfigurasi router dimana port ethernet akan menjadi DHCPclient dari routerADSL speedy

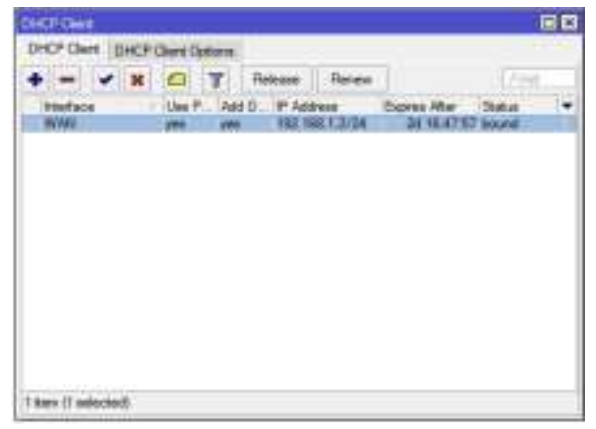

\section{Gambar 6. Tampilan menu DHCP Client}

5. Tambahkan interface WAN untuk menjadi Client DHCP dari Router ADSL speedy

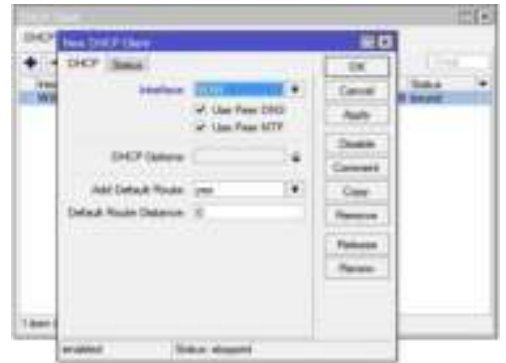

\section{Gambar 7. Tampilan menu Interface WAN}

6. Buka Menu IP lalu addresses untuk melihat apakah WAN sudah mendapatkan IP dari router ADSL speedy, dari gambar diatas interface WAN telah mendapatkan IP.

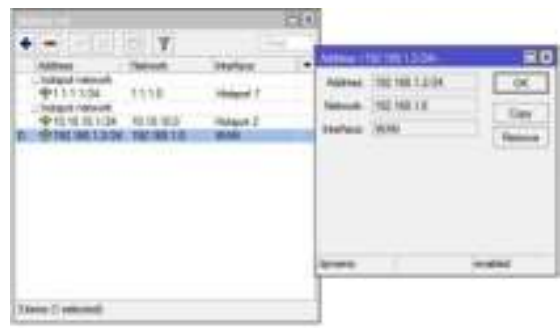

\section{Gambar 8. Tampilan menu IP}

7. Buka menu hotspot untuk melakukan pengaturan hotspot, pada perangkat mikrotik RB 411UAHR terdapat 2 radio pemancar wifi sehingga penulis dapat membuat 2 hotspot pada tempat penelitian

\section{Gambar 9. Tampilan menu hotspot}

8. Pilih interface untuk hotspot 1

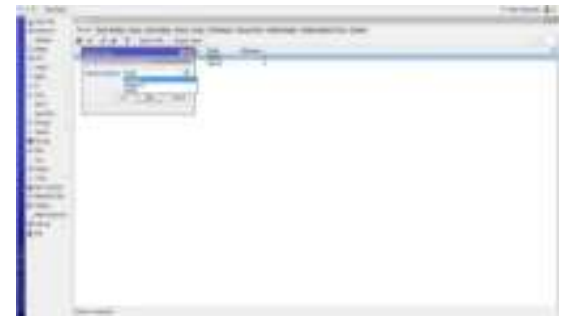

Gambar 10. Tampilan menu Interface untuk hotspot 1

9. konfigurasi IP addresshotspot 1

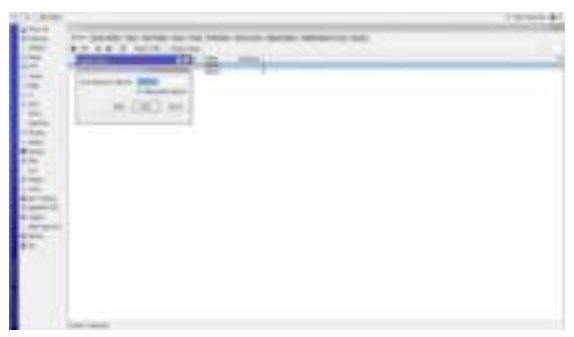

Gambar 11. Tampilan menu konfigurasi $I P$ address hotspot 1

10. Menu address pool untuk menentukan jumlah IP yang bisa terkoneksi ke hotspot

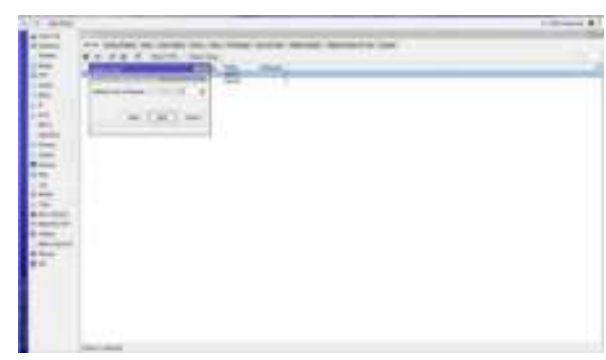

Gambar 12. Tampilan menu Address Pool

11. Isikan DNS dengan DNS google lakukan langkah yang sama ketika akan membuat hotspot dengan interface hotspot 


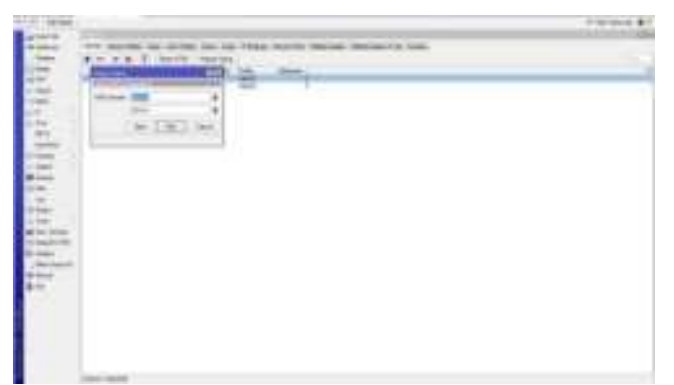

Gambar 13. Tampilan menu DNS

12. Daftar alamat IP pada perangkat interface router

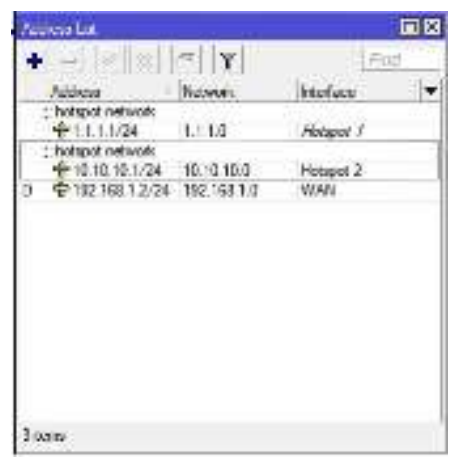

\section{Gambar 14. Tampilan menu Alamat IP}

13. Menu untuk menambahkan USER pada hotspot agar pengguna harus login terlebih dahulu untuk menggunakan fasilitas internet

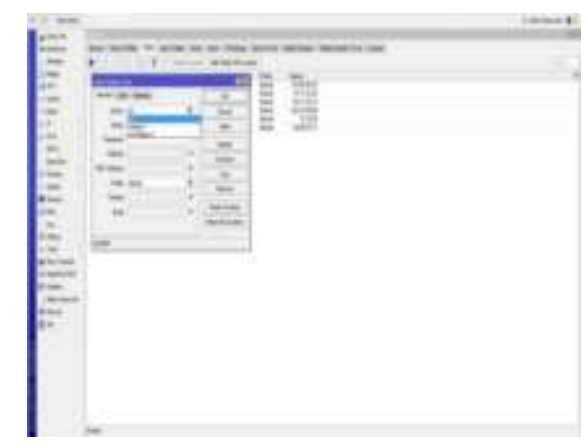

Gambar 15. Tampilan menu User Pada

$$
\text { Hotspot }
$$

14. Mengisikan nama USER

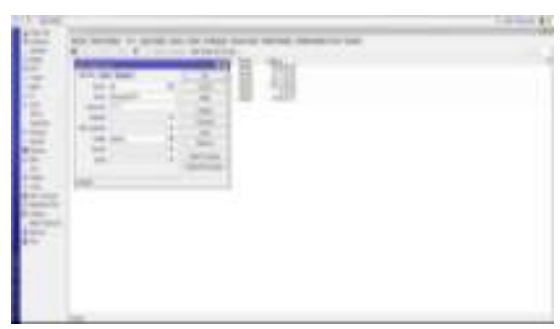

Gambar 16. Tampilan menu Nama User
15. Daftar User pengguna hotspot di BPU Bagas Raya

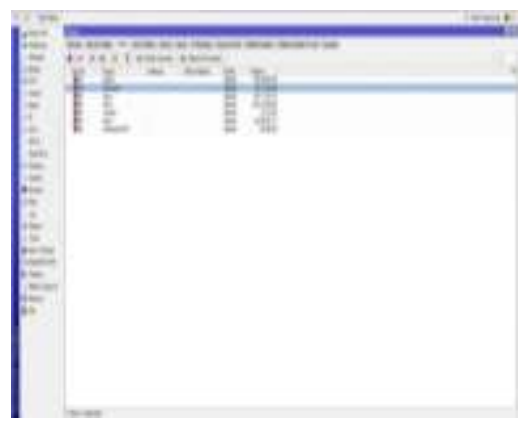

Gambar 17.. Tampilan menu User Hotspot BPU Bagas Raya

16. Daftar User yang sedang terkoneksi ke internet

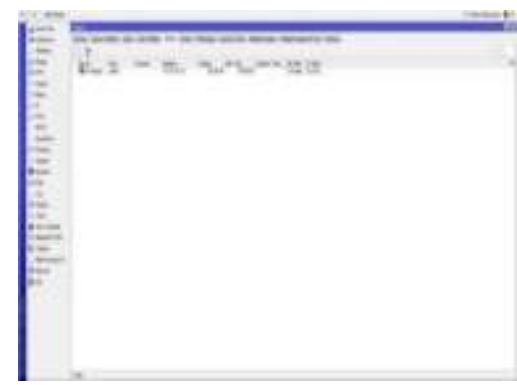

Gambar 18. Tampilan Daftar UserTerkoneksi Internet

\subsection{Monitoring}

NDLC mengkategorikan proses pengujian pada tahapan monitoring. Hal ini dikarenakan pengawasan sistem yang sudah dibangun hanya dapat dilakukan jika sistem sudah dapat bekerja sesuai dengan kebutuhan. Proses pengujian (testing) dibutuhkan untuk menjamin dan memastikan bahwa sistem yang dibangun sudah memenuhi spesifikasi rancangan.

\subsubsection{Hasil Pengujian Dengan Menggunakan}

\section{Ping Test}

Setelah selesai melakukan konfigurasi Mikrotik Routerboard, maka dilakukan ujicoba konektifitas terhadap jaringan pada masingmasing user.pengujian dilakukan dengan menggunakan PING TEST ke alamat defaulr 
google secara real time. Pada pengujian ini dilakukan dengan menggunakan dua komputer saja.Pengujian yang dilakukan yaitu dengan masuk ke dalam Command Prompt dengan mengetik "CMD" pada menu search windows. Setelah masuk ke jendela Command Prompt, maka ketikkan "ping 8.8.8.8-t -1 1" dimana data diambil per 1 byte.

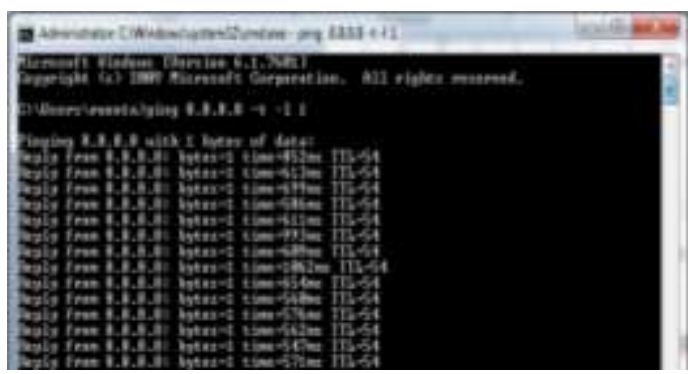

Gambar 19. Uji Konektifitas Dengan Menggunakan PING TEST

3.2.2.Hasil Pengujian Dengan Ping Flood DNS Google

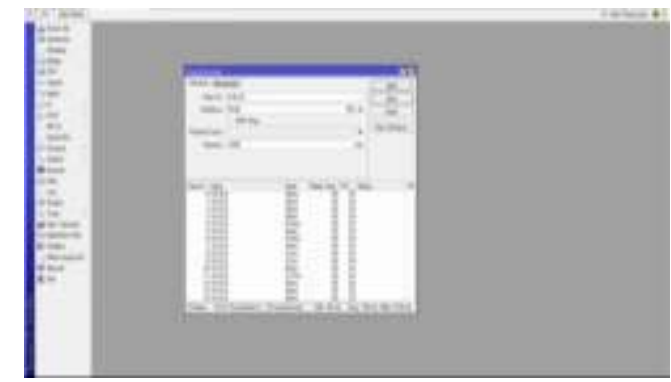

Gambar 20. Uji Konektifitas Ping Flood DNS Google

\subsubsection{Hasil Pengujian Dengan Melakukan} Ping ke IP Google Pada Laptop Client

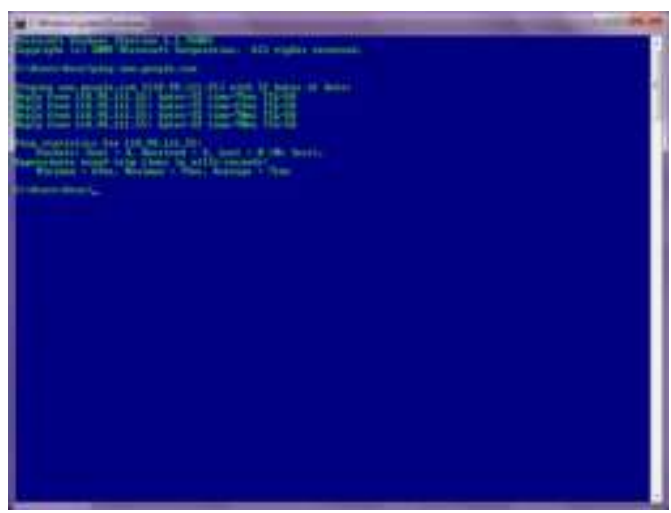

Gambar 21. Uji Konektifitas Ping IP Google PadaLaptop Client

\subsection{Managemen}

Fase terakhir pada model NDLC adalah managemen (pengelolaan). Fase ini meliputi aktifitas perawatan dan pemeliharaan dari keseluruhan sistem yang sudah dibangun. Namun, seperti penulis jelaskan sebelumnya bahwa tahap pengelolaan merupakan kewenangan dari pihak Managemen BPU Bagas Raya, maka penulis hanya terlibat sampai fase sebelumnya yaitu monitoring.

\section{SIMPULAN}

Dari Dari hasil uraian diatas, maka didapat suatu kesimpulan antara lain :

1. Dengan adanya jaringan HotSpot di kantor BPU Bagas Raya, akan mempermudah pengelola gedung dan juga pengunjung gedung dalam mengakses jaringan internet.

2. Sistem keamanan yang digunakan pada jaringan wireless (access point) ini sudah diatur oleh server, sehingga saat ingin mengakses internet, user harus memasukan username dan password.

Jaringan ini menggunakan DHCP server, sehingga server membagi IP Address sebanyak 
mungkin yang mengakibatkan loading yang

lama pada saat banyak user yang aktif.

\section{RUJUKAN}

Hallberg, Bruce. 2001. Networking: A beginner

Guide, Second Edition. Mc Graw-Hill.

California

Hardana and Irvant ino, 2011. Konfigurasi Wireless Routerboard Mikrotik. Yogyakarta : Andi.

Herlambang. M.Linto. 2009. Panduan Lengkap Membangun Sharing Koneksi Internet di Windows, MikroTIK, Linux, \& OpenBSD. Yogyakarta: Penerbit Andi.

Jogiyanto. 2005. Analisis dan Desain Sistem.Yogyakarta : Penerbit Andi

Ramadhan, A. 2006. Pengenalan Jaringan

Komputer. Jakarta : Elex Media Komputindo

James E. Goldman and Philip T. Rawles. 2001. Applied Data. Communications A BusinessOriented Approach. Mishawaka, US 